\title{
Analysis of occupant kinematics and dynamics in nearside oblique impacts
}

Lopez-Valdes $\mathrm{FJ}^{1}$, Juste-Lorente $\mathrm{O}^{1}$, Maza-Frechin $\mathrm{M}^{1}$, Pipkorn $\mathrm{B}^{2}$, Sunnevang $\mathrm{C}^{2,3}$, Lorente $\mathrm{A}^{1}$, Aso $\mathrm{A}^{4}$, Davidsson $\mathrm{J}^{5}$

${ }^{1}$ Impact Laboratory, Institute of Engineering Research of Aragon (I3A), University of Zaragoza, Spain

${ }^{2}$ Autoliv Research, Sweden

${ }^{3}$ Department of Surgical and Perioperative Science, Umeå University, Sweden

${ }^{4}$ Hospital Miguel Servet, Zaragoza, Spain

${ }^{5}$ Chalmers University

Corresponding author: Francisco J. Lopez-Valdes

Impact Laboratory, I3A, University of Zaragoza

Edif. I+D+i, Universidad de Zaragoza, c/Mariano Esquillor s/n

50018 Zaragoza, Spain

Phone: +34 978830172 Fax: +34 976762043

Word count (excluding abstract, acknowledgements and references): 4438 


\section{ABSTRACT}

\section{Objective}

The objective of the paper is to analyze the kinematics and dynamics of restrained Post Mortem Human Surrogates (PMHS) exposed to a nearside oblique impact and the injuries that were found after the tests.

\section{Methods}

Three male PMHS of similar age (64 \pm 4 years) and anthropometry (weight: $61 \pm 9.6$ kg; stature: $172 \pm 2.7 \mathrm{~cm})$ were exposed to a 30 deg nearside oblique impact at $34 \mathrm{~km} / \mathrm{h}$. The test fixture approximated the seating position of a front seat occupant. A rigid seat was designed to match the pelvic displacement in a vehicle seat. Surrogates were restrained by a three-point seat belt consisting of a $2 \mathrm{kN}$ pretensioning (PT), $4.5 \mathrm{kN}$ force-limiting shoulder belt and a $3.5 \mathrm{kN}$ PT lap belt. The shoulder belt PT was not fired in one of the tests. Trajectories of the head, shoulder and hip joint (bilaterally) were recorded at $1,000 \mathrm{~Hz}$ by a three-dimensional (3D) motion capture system. The 3D acceleration and angular rate of the head, T1 and pelvis, and the 3D acceleration of selected spinal locations were measured at 10,000 Hz. Seat belt load cells measured the belt tension at four locations. PMHS donation and handling were performed with the approval of the relevant Regional Ethics Review Board.

\section{Results}

The activation of the shoulder PT reduced substantially the peak forward excursion of the head but did not influence the lateral displacement of the head CG. In all the three subjects, the lateral excursion of the head CG (291.1 mm, 290 mm, $292.1 \mathrm{~mm}$ ) was greater than the forward displacement (271.4 mm, $216.7 \mathrm{~mm}, 171.5 \mathrm{~mm})$. The hip joint excursion of the PMHS that was not exposed to the shoulder PT seat belt was twice the magnitude observed for the other two subjects. The three PMHS sustained clavicle fractures on the shoulder loaded by the seatbelt and two of them were diagnosed atlantoaxial subluxation in the radiologist examination. Avulsion fractures of the right lamina of T1, T2, T3 and T4 were found when the PT was not used. The three PMHS received multiple fractures spread over both aspects of the rib cage and involving the posterior aspect of it.

\section{Conclusion}

In this study of nearside oblique impact loading, the PMHS exhibited kinematics characterized by reduced torso pitching and increased lateral head excursion as compared to previous frontal impact results. These kinematics resulted into potential cervical and thoracic spinal injuries and into complete, displaced fractures of the lateral and posterior 
aspects of the rib cage. While this is a limited number of subjects, it shows the necessity of further understanding of the kinematics of occupants exposed to this loading mode. 


\section{INTRODUCTION}

Serious and fatal injuries to restrained occupants in modern vehicles are common in crashes with limited engagement of the front structure (Lindkvist et al. 2004; Brumbelow and Zuby, 2009). After very severe frontal crashes with large change of velocity, oblique and small overlap crashes are the second most common crash type leading to fatal injury (Beam et al 2009). In these small overlap crashes, most frequent injuries to the nearside seated occupant are injuries to the head, chest and lower extremities. The oblique loading affects the intrusion into the occupant compartment as well as occupant kinematics. Due to the rotation of the vehicle, a lateral force is introduced during the crash influencing the injury outcome. Injury sources are listed as contact to A-pillar, steering wheel, instrument panel, door panel or from the interaction with the airbag and seat belt (Lindkvist 2006, Hallman et al. 2011, Rudd et al. 2011, Mueller et al. 2011).

To enhance occupant protection in frontal crashes, the Insurance Institute for Highway Safety (IIHS) introduced the small overlap load case in their consumer rating portfolio. For the USNCAP upgrade (MY19) the National Highway Traffic Safety Administration (NHTSA) is proposing another type of oblique load case called NHTSA Oblique. In the IIHS small overlap test the vehicle is crashed into a rigid barrier in $64.4 \mathrm{~km} / \mathrm{h}$ with $25 \%$ overlap using the Hybrid III (HIII) 50\% male for injury assessment (IIHS 2014). In the NHTSA proposal for oblique loading a moving deformable barrier is crashed at 15 degree angle with a $35 \%$ overlap into a still standing vehicle at $90 \mathrm{~km} / \mathrm{h}$. The THOR-M (Test Device for Human Occupant Restraint- Metric) dummy in driver and passenger seat is proposed for injury assessment (Saunders et al. 2015). The THOR-M is defined as the THOR-NT dummy, including the Modification Kit and the SD3 shoulder (NHTSA; Parent et al, 2013)).

Different anthropometric test devices have been evaluated in crash scenarios replicating oblique and small overlap crashes. A comparison between the HIII and THOR in the IIHS small overlap crash test showed no difference in injury outcome (Mueller et al. 2011). However a comparison in a sled test setup using a pre deformed door and small overlap crash pulse showed differences in kinematics between HIII and THOR as well as potential injury caused by contact to the door using the THOR dummy (Sunnevång et al. 2014). Comparing the THOR with the HIII and Post Mortem Human Surrogate (PMHS) tests in frontal impacts have demonstrated improved biofidelity of THOR over the HIII (Parent et al. 2013, Shaw et al. 2000, Yoganandan et al. 2011). With the more humanlike kinematic behavior and increased thoracic sensitivity of THOR-M it is believed that the THOR-M is a suitable tool for evaluating occupant injury risk in oblique impacts (Sunnevång et al. 2014). 
The complexity of the crash, with potential intrusion affecting the injury outcome, as well as interaction with the seat, airbags and seat belt makes difficult to assess the suitability of THOR in oblique impacts as well as to understand the different injury mechanisms. In this study, and to ensure that the kinematics of the occupant could be completely characterized, it was decided to focus just on the occupant's interaction with the simplified rigid seat and three point seat belt, excluding the effects of airbags and vehicle structure. Similar reasoning had been used in previous oblique sled impacts, either nearside or farside (Horsch, 1980). Thus, the term nearside impacts is used here to mean that the occupant's belted shoulder was on the impact side.

The goal of this study is to provide fundamental information about the kinematics observed in three PMHS nearside oblique tests using contemporary restraints, including the discussion about potential injury sources..

\section{METHODS}

Three Post Mortem Human Surrogates (PMHS) were exposed to a nearside oblique impact at 30 degrees resulting in a nominal change of velocity of $34 \mathrm{~km} / \mathrm{h}$. The impact angle was chosen to allow the comparison to other PMHS sled tests reported in the literature (Iraeus et al., 2013; Kallieris et al., 1982; Tornvall et al., 2005) and with previous investigations on the feasibility of using the THOR dummy as a valid surrogate to evaluate head and chest injuries in near-side oblique impacts (Sunnevang et al., 2014). The aforementioned PMHS sled tests were performed at speeds similar to the one chosen in this study (26.6 km/h and $30 \mathrm{~km} / \mathrm{h})$. In addition, previous sled tests with THOR and PMHS had been run at $34 \mathrm{~km} / \mathrm{h}$ in frontal configuration with the same restraints (Pipkorn et al., 2015; Lopez-Valdes and Juste-Lorente, 2015) .The test matrix is included in Table 1. The time history of sled deceleration is included in Figure A1 in the Appendix. Vehicle yaw rotation typical of oblique impacts was not considered.

\section{Test setup}

The test fixture consisted of a rigid metallic frame allowing complete visual access to the occupant while preserving the basic geometry of a standard seating position of a passenger car. This test fixture has been used elsewhere as a reasonable approximation to the passenger posture in studies of ATD biofidelity and in the development of thoracic injury criteria (Lopez-Valdes et al., 2010; Lopez-Valdes et al., 2014; Shaw et al., 2009). The seat consisted of a customized arrangement of rigid steel plates designed to arrest the forward excursion of the pelvis similarly to a commercial vehicle seat . Forward motion of the subjects was restrained by a shoulder (2 kN) and lap (3.5 kN) pretensioned, force-limiting $(4.5 \mathrm{kN})$ at the shoulder seatbelt $(\mathrm{PT}+\mathrm{FL})$. The shoulder pretensioner was not fired in the 
test with the subject PMHS 1. The position of the D-ring was adjusted so that the belt geometry was similar across the different sizes of occupants (i.e. to maintain the angle between the belt band and the horizontal). The belt was replaced after each test. Upper shoulder belt tension was measured at an intermediate position between the shoulder of the occupant and the D-ring, while lower shoulder belt tension was measured at $10 \mathrm{~cm}$ from the attachment of the belt latch. Lap belt tension was measured bilaterally. All sensor data were captured at 10,000 Hz with an external data acquisition system (PCI-6254, National Instruments; Austin, TX). Tests were recorded by a lateral and a frontal highspeed imager at $1,000 \mathrm{~Hz}$.

\section{PMHS characteristics and procedures}

Procurement, handling and testing of the PMHS was done under the approval of the Ethical Commission for Clinical Research of Aragon (CEICA), which is the official body responsible for assessing all research projects involving human subjects in the region of Aragon. Table 1 summarizes the main characteristics of the PMHS. Average age was 64.6 years old (standard deviation (SD): 4.2 years), average stature was $172.0 \mathrm{~cm}$ (SD: $2.7 \mathrm{~cm}$ ) and average weight was $61.0 \mathrm{~kg}$ (SD: $9.6 \mathrm{~kg}$ ). Triaxial accelerometers were rigidly attached to the top of the head, two locations on the thoracic spine (upper and middle regions, nominally T1 and T8), lumbar spine (L2) and the pelvis (see Table 1). Triaxial Angular Rate Sensors (ARS) were added to the head, upper spine and pelvis. Linear acceleration was measured at the the sternum body. Computed tomography (CT) scans were taken prior to test, to ensure that there were not previous conditions that could compromise the results of the study, and post tests to assist in the injury assesment. PMHS were also subjected to a post-test detailed autopsy.

\section{Marker position. Data processing}

Retro-reflective spherical markers were attached to selected locations on the head; upper, mid and lower sections of the spine; acromion bilaterally, sternum, pelvis, hip joint bilaterally and on the $4^{\text {th }}$ and $8^{\text {th }}$ ribs bilaterally. Marker clusters were used on the head, ribs, sternum, spine and pelvis. Clusters were attached using rigid, low-weight aluminum plates to the corresponding anatomical structure. All analyses were done until the time in which it was not possible to continue tracking the markers due to the motion of the occupant. This time is indicated in the subsequent plots and varies across subjects. The analyses included in this study consider only the mid-point between the two head bilateral markers that were placed approximately at the external auditory meatus (head CG), the mid-point between 
the two markers placed at the acromion bilaterally (mid-Ac) and the two markers placed at palpable location of the greater trochanter bilaterally (mid-HP).

\section{Motion capture system}

Kinematic data were collected at $1000 \mathrm{~Hz}$ using an optoelectric stereophotogrammetric system consisting of 10 cameras (Vicon, TS series, Oxford, UK). The system captured the position of the aforementioned retro-reflective spherical markers within a calibrated 3D volume. A calibration procedure, performed prior to testing, estimated the optical characteristics of each camera and established its position and orientation in a reference coordinate system. The trajectory of each marker was recorded and smoothed through a rigidity constraint using the least squares pose (LSP) estimator (Cappozzo et al., 2005; Chiari et al., 2005; Della Croce et al., 2005; Leardini et al., 2005). A global coordinate system (GCS) was defined at a laboratory fix location. A local coordinate system (LCS) moving with the test buck was defined with origin at the front right corner of the seat following SAE J211 indications (Society of Automotive Engineers, 1998). Local x axis pointed forward and it was coincident initially with the frontal anatomical axis of the occupant. The vertical $\mathrm{z}$ axis pointed upwards (opposite to ground) and the y axis was defined to form a right-hand oriented coordinate system. Unless otherwise indicated, displacement data are expressed with respect to this LCS. A photogrammetric algorithm within the Vicon Nexus software package (Nexus 1.8.5, Vicon, Oxford, UK) reconstructed the 3D position of each target for each video sample increment from the multiple 2D camera images.

\section{RESULTS}

Table 1 summarizes the main kinematic and dynamic parameters measured during the tests.

\section{Trajectories in sagittal and frontal planes}

The trajectories of the head CG, mid-Ac and mid-HP in the occupant's sagittal and frontal anatomical planes are shown in Figure 1 and Figure 2. Due to loss of visual access to the head and hip joint bilateral markers, the trajectory of the head could be calculated only up to t=91 ms for the three PMHS and the trajectory of PMHS 1 mid-HP up to $\mathrm{t}=66 \mathrm{~ms}$. The rest of the trajectories were tracked up to $\mathrm{t}=120 \mathrm{~ms}$. PMHS 1 exhibited the largest head CG forward excursion $\left(\delta_{\mathrm{x}}=271.4 \mathrm{~mm}\right)$ followed by PMHS 2 and PMHS 3. Despite of the similar restraint conditions between PMHS 2 and PMHS 3, PMHS 3 head CG excursion was substantially shorter than PMHS 2's one (171. 5 mm vs. 216.mm). Interestingly, peak lateral displacement (local y-axis direction) of the head CG was larger than the forward one consistently for the three subjects. The three PMHS showed similar trajectories in the frontal plane, with the 
magnitude of the head CG y-displacement ranging between $292.1 \mathrm{~mm}$ and $290 \mathrm{~mm}$ (Figure 2). The use of the shoulder PT induced a more curvilinear head trajectory, while the trajectory of the head CG of PMHS 1 was closer to a right angle with an initial translation mostly parallel to the $\mathrm{y}$ axis followed by a translation nearly parallel to the $\mathrm{z}$ axis. In the sagittal plane, the peak forward excursion of the mid-HP without PT was twice the magnitude of the peak displacement of the same landmark when the PT+FL seat belt was used (51.2 mm vs. 20.9 and $21.9 \mathrm{~mm}$ ). Similar trend was exhibited at the mid-Ac location.

Figure A.2 shows selected high-speed video frames at different times to illustrate the global kinematics of the three occupants in these tests. It should be noted the extreme cervical flexion occurring at $\mathrm{t}=130 \mathrm{~ms}$ and later.

\section{Interaction between the occupants and the restraint system}

Upper shoulder belt time history is shown in Figure 3. The belt force corresponding to the test without PT (PMHS 1) started to build at around $\mathrm{t}=30 \mathrm{~ms}$, while the PT contributed to an earlier engagement between the occupant's torso and the seat belt. It was necessary to wait until $\mathrm{t}=50 \mathrm{~ms}$ for the shoulder belt without PT to reach the level of the initial pretensioning force (occurring at $\mathrm{t}=19 \mathrm{~ms}$ ). Consequently, the time trace of PMHS 1 shoulder belt force was narrower and exhibited a larger peak value than the corresponding one of the other two subjects (4325 N vs. $3623 \mathrm{~N}$ and 3695 $\mathrm{N}$ ). The three occupants started to unload the shoulder belt at approximately the same instant (approximately $85 \mathrm{~ms}$ after the beginning of the deceleration). The magnitude of the shoulder belt force was larger at the lower measuring location, indicating that the lower rib cage received a substantial amount of belt loading during the deceleration. PMHS 1's lower shoulder peak belt force was 4845 N, PMHS 2's was 3853 N and PMHS 3's was 4304 N. As for the lap belt forces measured bilaterally on the lap portion, there were not substantial differences between the peak magnitudes measured in the three PMHS tests. The values are included in Table 2.

The evolution of the torso angle ( $\beta$, defined as the angle between the line connecting the Mid-Ac with the Mid-HP and the horizontal) during the deceleration is included in Figure 4. Note that this angle could be calculated only up to $\mathrm{t}=66 \mathrm{~ms}$ in the case of PMHS 1. Although the three subjects were positioned before test in a similar way using external body landmarks (resulting in equivalent initial positions), the calculation of the torso angle $\beta$ from the reflective markers showed that PMHS 1 was slightly closer to the vertical $\left(\beta_{\text {PMHS }}=116\right.$ deg).. Despite the minor differences in the initial value of the calculated torso angle (8 degrees at its maximum), the three PMHS exhibited a similar torso flexion motion far from reaching the point of $\beta=90 \mathrm{deg}$. The time history trace of angle $\beta$ is shown in Figure 4 . 
The time history of the lap belt forces measured in the tests is included in the Appendix (Figure A.3)

\section{Description of injuries}

The injuries found during the post-test CT examination and the autopsy are summarized in Table 2. Some of the injuries found in the CT examination could not be observed in the autopsy of the bodies. CT radiologist were kept blind to the results of the autopsy, but not the other way round. The radiologists diagnosed symptoms of rotational subluxation of the atlantoaxial joint of PMHS 1 and PMHS 3 that were consistent with the kinematics observed in the tests (see video captures at $\mathrm{t}=130 \mathrm{~ms}$ and $\mathrm{t}=150 \mathrm{~ms}$ in Figure A.2). There was evidence of neck abrasion due to the seat belt only in PMHS 3. The analysis of the high-speed video did not show that the shoulder belt moved towards the neck during the initial phase of chest loading. However, in the three experiments the shoulder band was lying against the lateral aspect of the neck during the rebound phase. The three subjects sustained fractures in the proximal area of the right clavicle. PMHS 1 and PMHS 3 received a displaced fracture, while PMHS 2 sustained a non-displaced minor fracture on the posterior aspect of the clavicle. Last, PMHS 2 also received a non-displaced fracture on the right pubic ramus.

The tables and figures included in the Appendix provide a detailed description of the rib cage injuries found in the autopsy (see Table A.1 through Table A.4 and Figure A.4 through Figure A.6).

\section{DISCUSSION}

To the knowledge of the authors, there are just a handful of sled test with PMHS subjected to oblique nearside impacts. (Iraeus et al., 2013) mentions two sled test series performed with PMHS at 30 degrees: one performed at $30 \mathrm{~km} / \mathrm{h}$ at the University of Heidelberg (Kallieris et al., 1982) and the second one performed at $26.6 \mathrm{~km} / \mathrm{h}$ at the University of Graz. Unfortunately, the data from the last one have not been published, although some information was included in (Iraeus et al., 2013). The data from Heidelberg have been revisited in more recent years in different publications (Kent et al., 2003; Tornvall et al., 2005; Iraeus et al., 2013). The combination of both sources provides data from eight PMHS. Thus, the current study adds data from three additional subjects

In this study, the introduction of a shoulder PT reduced the forward excursion of the head CG similarly to what had been already reported in frontal impacts (Forman et al., 2008; Forman et al., 2009; Lopez-Valdes et al., 2009). However, the peak head excursion in the forward direction was not considered a relevant risk factor for injury as it was limited to less than $275 \mathrm{~mm}$. On the contrary, the lateral motion of the head was substantially higher than the one 
observed in the forward direction. In this case, the inclusion of the shoulder belt PT did not influence the peak lateral excursion of the head CG. As these impacts are nearside oblique, the measured y-peak excursion close to $300 \mathrm{~mm}$ could be a significant risk of head contact against the side structure of the vehicle (if no inflatable countermeasure is present).

The comparison of the lap belt forces can be an explanation of the excessive pelvic motion exhibited by PMHS 1. The combination of the shoulder PT and lap seat belt PT arrested the forward motion of the pelvis more effectively than just the lap belt PT. It can be seen in the comparison of the inner and outer lap belt forces that while the seat belt force trace is comparable at the outer lap belt location across the three subjects (where the lap belt PT was located), the time history of the inner lap belt force is completely different for the two PMHS that used a shoulder PT. In these two cases, the lap belt force reached up to $3.5-4 \mathrm{kN}$ force early in the deceleration (at around $\mathrm{t}=20 \mathrm{~ms}$, due to the activation of the lab belt PT) while the non-shoulder PT seatbelt only reached this force level at $t=70$ ms. Figure A.3 also shows that, after the initial peak tension and the subsequent tension drop, there was a second drop in lab belt tension (observed at both the inner and the outer measuring locations) at around $\mathrm{t}=50 \mathrm{~ms}$ in the tests with PMHS 2 and 3 that was not observed in the first test. While these sudden drops in tension could be indicative of submarining, the post-test inspection of the subjects confirmed that the lap belt was still engaged by the pelvis. In addition, no internal organ injuries were found in the autopsy.

The comparison between the kinematics reported here and the ones from the Heidelberg tests can be done thanks to the comparison between THOR, the Hybrid III and the Heidelberg PMHS tests included in (Tornvall et al., 2005). While the magnitude of the lateral head and shoulder excursions measured in the Heidelberg tests (300-400 mm) is comparable to the ones measured in this study, the forward excursion of these landmarks were much larger (400-500 $\mathrm{mm})$. The difference can be more likely attributed to the use of the shoulder and lap belt pretensioner in these tests and to the fact that only the unbelted side of the occupant could be tracked by the high-speed video cameras in the Heidelberg tests. It should be noted that the combination of the slender PMHS and the moderate test speed resulted into relatively small shoulder belt forces below the force-limiting feature of the seat belt ( $4.5 \mathrm{kN})$. Greater forward excursion of the head and flexion of the torso are to be expected if the belt pays out during the tests. Previous sled tests comparing the performance of relatively similar PT+FL seat belts to standard seat belts without pretensioning and force limiting features showed that occupant's kinematics were improved with the PT+FL system, as the FL feature will benefit increased torso pitch (Forman et al, 2008; Forman et al, 2009; Lopez-Valdes et al, 2009). 
In our tests, the interaction between the seat belt and the occupant could not be considered optimal according to the design guidelines proposed by Adomeit and Heger (1975). Traditionally, the design of optimal restraints seeks to load hard areas of the body (pelvis, clavicle, sternum and upper part of the rib cage) and to avoid submarining. Seminal studies established that a vertical downward motion of the H-point should be avoided while forward rotation of the torso ideally beyond the vertical should be facilitated (Adomeit and Heger, 1975; Adomeit, 1979). While the postulate regarding the motion of the pelvis can be considered achieved by the restraints used in the tests, Figure 4 showed that in none of the three cases the torso angle passed the vertical orientation. The consequence of the reduced torso rotation is that the seat belt shoulder forces would act primarily over the lower part of the rib cage instead of on the upper region. While other factors may have contributed to it, PMHS 1 and PMHS 2 sustained a substantial number of rib fractures in the lower area of the rib cage bilaterally. The THUMS simulations performed in (Iraeus et al., 2013) and benchmarked against the Graz and Heidelberg data showed a pattern of rib fractures involving the upper rib levels on the belted shoulder (outboard) and distributed fractures involving the lower rib cage on the inboard ribcage aspect, which is partially consistent with our results.

The injury list provided in the study combines the diagnosis done by radiologists with the findings from the post-test autopsy. Radiologists' diagnosis was performed prior to the autopsy. The autopsy examination was guided by the previously obtained CT report. Underreporting of injuries based on radiology diagnoses had been already discussed in the literature (Crandall et al., 2000), but some of the injuries diagnosed in the CT examination could not be found in the autopsy. These were not included in the study. Contrarily, the CT post-test suggested evidence of subluxation at the atlantoaxial joint in PMHS 1 and PMHS 3, which are ligamentous injuries difficult to identify in the autopsy. The occurrence of clavicle fractures in the three subjects, regardless of the use of shoulder belt PT, suggests a poor interaction between the occupant and the restraint in this loading configuration. Given that the pulse selected was mild with a delta-v of only $34 \mathrm{~km} / \mathrm{h}$ and that the upper shoulder belt forces were relatively low compared to similar frontal PMHS tests, this finding indicates that the additional torso rotation in the occupant's longitudinal axis induced by the oblique impact might have increased the likelihood of clavicle fractures. This torso rotation is also most likely the cause of the lateral/posterior right aspect rib fractures found in the autopsy. In the vast majority of the cases, these fractures were complete and displaced causing instability of the rib cage. The vertebrae fractures found at the right lamina (including unstable transversal processes) of T1, T2, T3 and T4 deserve special attention as these fractures might have caused spinal cord damage in a living occupant. Coincidentally, these fractures were observed only in the 
test in which the shoulder PT was not fired. However, the radiologists diagnosed a bilateral transverse process fracture at L3 in PMHS 2 and a left lamina fracture of C7 in PMHS 3 that could not be observed in the autopsy despite a detailed dissection of the relevant area.

In the series of cadaveric sled tests performed at $30 \mathrm{~km} / \mathrm{h}$ at the University of Heidelberg, only rib and sternal fractures were found in the 30 deg nearside impacts. The average number of rib fractures was 3.2 and only two subjects out of the five that were tested sustained sternal fractures. Peak shoulder belt forces were always under $3.8 \mathrm{kN}$, similar to the peak forces found in this study. The main differences with this study are the production seat used in the Heidelberg tests and the average younger age of the PMHS. Whether these two reasons explain completely the differences in injury outcome cannot be determined with the information available (Kent et al., 2003). The Kent et al. (2003) study revisited the Heidelberg test series and compared them with dummy tests in matching conditions, concluding that there were not substantial differences between the injury pattern found in the frontal and oblique sled tests (up to 45 deg). A similar conclusion was predicted for the human based on a series of nearside and far-side oblique dummy tests in the 1970s (Adomeit et al., 1977). On the contrary, a parametric study carried out with THUMS (Iraeus et al., 2013) showed substantial increase of AIS3+ chest injuries when the impact angle increased from -15 deg to -45 deg in 10 deg intervals and for increasing values of delta-v (for example, predicted risk was 0.08, $0.15,0.84$ and 0.93 for -15 deg, -25 deg, -35 deg and -45 deg at $40 \mathrm{~km} / \mathrm{h})$.

Adomeit et al. also indicated that neck injuries could be expected in the nearside configuration, although none of these were found in the Heidelberg tests. Similar concerns about neck injuries were also expressed in the dummy sled tests described in (Hontschik and Ruter, 1980) and (Horsch, 1980), although the use of dummies prevents from establishing a more detailed comparison with the present study. While the results included here confirm the predicted higher neck injury risk suggested by Adomeit et al (1977), Hontschik and Ruter (1980) and Horsch (1980), the comparison of the these tests with frontal sled PMHS performed in similar conditions (Lopez-Valdes et al., 2010; Lopez-Valdes et al., 2014) does not support the insensitivity of the resulting injury pattern to the impact direction proposed by Kent et al. (2003) and Adomeit et al (1977).

\section{Limitations}

The complex kinematics of the occupant made difficult to have visual access to all markers at all times. In fact, the rotation of the subject along the front and longitudinal axis, with the left aspect of the torso wrapping around the 
seatbelt covered the right torso markers during several milliseconds. Similarly, the swing of the right arm covered the right head marker from $\mathrm{t}=91 \mathrm{~ms}$ onwards. The plots presented in the study were produces up to the time in which there was no more visual access to the markers. Although this is clearly a limitation of the method, there is no other technique that allows to reconstruct the kinematics with this level of detail. In future tests, amputation of the arms of the PMHS might be advisable to minimize the interaction of the upper extremities with the head and anterior chest markers. It should be noted that, despite this limitation, the peak forward head position was reached before t=91 ms.

The three PMHS died from cancer. Although efforts were made to ensure that there was not bone metastasis, the extent of the influence of this health condition on the bone quality is unknown. In addition, the pre-test CT scan of PMHS 2 had indicated previously healed fractures of the left ilium and left ischium. The pelvic fractured observed in the post-test CT was on the right pubic ramus (subject's aspect that was primarily load due to the kinematics) and thus, it is not related to the pre-existing healed ones.

Occupants were slightly shorter and lighter than the common $50^{\text {th }}$ percentile, however they were of very similar anthropometry and age. The homogeneity of these characteristics was valued more importantly than any other consideration of being anthropometrically representative of the population.

The test fixture used in the tests approximated the seating position of a front occupant in a simplified and repeatable manner that is also easy to implement using human body models. The seat belt geometry is based in a mid-size vehicle and it has been used before in the literature (Lopez-Valdes et al., 2014; Shaw et al., 2009). The seat of the previously used buck was modified to mimic better the displacement of the pelvis of the human occupant in a production seat. Despite of being completely rigid, the geometry was adapted so that the pelvic sagittal displacement observed in THUMS simulations of frontal impacts would be comparable to the same displacement in a real vehicle seat.

\section{CONCLUSSION}

Three Post Mortem Human Surrogates (PMHS) of approximately the same age and anthropometry were exposed to a nominal change of velocity of $34 \mathrm{~km} / \mathrm{h}$ in an oblique nearside impact at 30 degrees measured from the longitudinal axis of the vehicle. PMHS were restrained by a pretensioned, force limiting belt at the shoulder band and a pretensioned lap band. The shoulder belt pretensioner was not fired in one of the tests, resulting in an increased forward excursion of the head center of gravity. However, the pretensioner did not influence the lateral head displacement that 
was greater than the peak forward one for the three subjects, at least for the subjects included in this study. The interaction of the occupants' torso with the restraint was not optimal regardless of the use of the shoulder belt pretensioner. The suboptimal interaction between the occupants and the seat belt resulted in kinematics that could be associated to potential cervical and thoracic spine injuries (atlanto-axial subluxation and avulsion fractures of transverse processes) and complete displaced injuries of the posterior/lateral aspect of the rib cage. The three subjects sustained right clavicle fractures likely caused by the combination of the seat belt loading and the increased torso rotation induced by the oblique loading direction. While this is a limited study due to the low number of subjects, it shows the necessity of understanding better the kinematics of occupants under oblique loading.

\section{ACKNOWLEDGEMENTS}

SAFER Vehicle and Traffic Safety Centre provided the funding to perform the experiments described in this paper in the framework of the project "Oblique load thorax". The study was partially funded also by the Instituto Aragones de Fomento of Gobierno de Aragon via the "Collaborative agreement to foster research on impact biomechanics”, signed on Feb 11th, 2015. The authors would like to thank Dr. Jose Aso and his colleagues from the Neurosurgery and the Radiology Depts. of Hospital MAZ for their assistance in the preparation of the bodies. This study shows solely the interpretation of the authors and is not necessarily the view of Autoliv Development AB, Chalmers tekniska hogskola $\mathrm{AB}$ or the Instituto Aragones de Fomento. The art drawings of the ribcage used in the Appendix were taking from the book Anatomy of the Human Body by Henry Gray (1918). Last, the authors wish to thank specially the donors and their families as, without their generous act, this study would have never existed. 


\section{REFERENCES}

Adomeit, D., 1979. Seat design - A significant factor for safety belt effectiveness. In Paper no. 791004. Society of Automotive Engineers. Warrandale, PA.

Adomeit, D., Goegler, H., Vu Han, V., 1977. Expected belt-specific injury patterns dependent on the angle of impact. In Proc. 3rd International Conference on Impact Trauma.

Adomeit, D., Heger, A., 1975. Motion sequence criteria and design proposals for restraint devices in order to avoid unfavorable biomechanic conditions and submarining. In Proceedings of the 19th Stapp Car Crash Conference. Warrandale, PA.

Bean J, Kahane C, Mynatt M. Fatalities in Frontal Crashes Despite Seat Belts and Air Bags - Review of All CDS Cases - Model and Calendar Years 2000-2007 - 122 Fatalities. NHTSA Technical Report: DOT HS 811 202, National Highway Traffic Safety Administration, US Department of Transportation, Washington, DC, 2009.

Brumbelow M, and Zuby D. Impact and injury patterns in frontal crashes of vehicles with good ratings for frontal crash protection. Proceedings of the 21st ESV Conference, paper number 09-0257, 2009: Stuttgart, Germany.

Cappozzo, A., Della Croce, U., Leardini, A., Chiari, L., 2005. Human movement analysis using stereophotogrammetry. Part 1: theoretical background. Gait \& Posture 21, 186-196.

Chiari, L., Della Croce, U., Leardini, A., Cappozzo, A., 2005. Human movement analysis using stereophotogrammetry. Part 2: instrumental errors. Gait \& Posture 21, 197-211.

Crandall, J., Kent, R., Patrie, J., Fertile, J., Martin, P., 2000. Rib Fracture Patterns and Radiologic Detection: A Restraint-Based Comparison. Annual Proceedings / Association for the Advancement of Automotive Medicine 44, 235-260.

Della Croce, U., Leardini, A., Chiari, L., Cappozzo, A., 2005. Human movement analysis using stereophotogrammetry. Part 4: assessment of anatomical landmark misplacement and its effects on joint kinematics. Gait \& Posture 21, 226-237.

Forman, J., Lopez-Valdes, F., Lessley, D., Kindig, M., Kent, R., Ridella, S., Bostrom, O., 2009. Rear seat occupant safety: an investigation of a progressive force-limiting, pretensioning 3-point belt system using adult PMHS in frontal sled tests. Stapp Car Crash Journal 53, 49-74.

Forman, J., Michaelson, J., Kent, R., Kuppa, S., Bostrom, O., 2008. Occupant restraint in the rear seat: ATD responses to standard and pre-tensioning, force-limiting belt restraints. Annals of Advances in Automotive Medicine. Association for the Advancement of Automotive Medicine Scientific Conference 52, 141-154.

Hallman J, Yoganandan N, Pintar F, et al. Injury Differences between Small and Large Overlap Frontal Crashes. Ann Adv Automot Med. 2011;55:147-57.

Hontschik, R., Ruter, G., 1980. Investigations into the efficacy of three-point seat belts in oblique impact experiments. In IRCOBI Proceedings. Bron (France).

Horsch, J. D., 1980. Occupant dynamics as a function of impact angle and belt restraint. In SAE Paper no. 801310.

IIHS. Small Overlap Frontal Crashworthiness Evaluation Crash Test Protocol (Version II). Rating Protocol from Insurance Institute of Highway Safety. 2012: Arlington. 
Iraeus J, Lindkvist M, Wistrand S, Sibgård E, Pipkorn B. Evaluation of Chest Injury Mechanisms in Nearside Oblique Frontal Impacts. Annu Proc Assoc Adv Automot Med. 2013;57:183-96.

Kallieris, D., Schmidt, G., Schueler, F., 1982. Thoraxbelastung und Verletzungsmuster bei der Schrägkollision. In Beitr Gerichtl Med.

Kent, R., Shaw, G., Lessley, D., Crandall, J., Kallieris, D., Svensson, M., 2003. Comparison of Belted Hybrid III, THOR, and Cadaver Thoracic Responses in Oblique Frontal and Full Frontal Tests. In SAE Paper no. 2003-010169 .

Leardini, A., Chiari, L., Della Croce, U., Cappozzo, A., 2005. Human movement analysis using stereophotogrammetry. Part 3. Soft tissue artifact assessment and compensation. Gait \& Posture 21, 212-225.

Lindkvist M, Hall A, Bjornstig U. Car Structural Characteristics of Fatal Frontal Crashes in Sweden, Int. Journal of Crashworthiness 2004, 9(6), 587-597.

Lindkvist M, Hall A, Björnstig U. Kinematics of belted fatalities in frontal collisions: A new approach in deep studies of injury mechanisms. Journal of Trauma. 2006; 61:1506 -1516.

Lopez-Valdes, F. J., Forman, J., Kent, R., Bostrom, O., Segui-Gomez, M., 2009. A comparison between a child-size PMHS and the Hybrid III 6 YO in a sled frontal impact. Annual Proceedings / Association for the Advancement of Automotive Medicine.Association for the Advancement of Automotive Medicine 53, 237-246.

Lopez-Valdes, F. J., Juste, O., Pipkorn, B., Garcia-Munoz, I., Sunnevang, C., Dahlgren, M., Alba, J. J., 2014. A comparison of the performance of two advanced restraint systems in frontal impacts. Traffic Injury Prevention 15 Suppl 1, S119-25.

Lopez-Valdes, F., Juste-Lorente, O. Innovative Restraints to Prevent Chest Injuries in Frontal Impacts. Paper No. 15-0381, Conference for the Enhancement of Safety Vehicles (ESV) 2015. Gothenborg (Sweden).

Lopez-Valdes, F. J., Lau, A., Lamp, J., Riley, P., Lessley, D. J., Damon, A., Kindig, M., Kent, R., Balasubramanian, S., Seacrist, T., Maltese, M. R., Arbogast, K. B., Higuchi, K., Tanji, H., 2010. Analysis of spinal motion and loads during frontal impacts. Comparison between PMHS and ATD. Ann Adv Automot Med. 54, 61-78.

Mueller B, Sherwood C, Arbelaez R, Zuby D, Nolan J. Comparison of Hybrid III and THOR dummies in paired small overlap tests. Stapp Car Crash Journal 2011: Vol 55, pp 379-409.

NHTSA. Available at: http://www.nhtsa.gov/Research/Biomechanics+\&+Trauma/THOR+50th+Male+ATD Last time visited: 04/11/2016.

Parent D, Craig M, Ridella S, McFadden J. Thoracic Biofidelity Assessment of the THOR Mod-Kit ATD. Proceedings of the 23rd ESV Conference, Paper No. 13-0327, 2013: Seoul, Korea.

Pipkorn B, Lopez-Valdes FJ, Lundgren C, Brase D, Sunnevang C. Innovative seat belt system for reduced chest deflection. Paper No. 15-0371, Conference for the Enhancement of Safety Vehicles (ESV) 2015. Gothenborg (Sweden).

Rudd R, Scarboro M, Saunders J. Injury analysis of real-world small overlap and oblique frontal crashes. Proceedings of the $22^{\text {nd }}$ ESV Conference, 2011: Washington D.C, USA. 
Saunders J, Parent D, Ames E. NHTSA oblique crash test results: vehicle performance and occupant injury risk assessment in vehicles with small overlap countermeasures. Proceedings of the $24^{\text {st }}$ ESV Conference, paper No 150108, 2015: Gothenburg, Sweden

Shaw G, Crandall J and Butcher J, 2000. Biofidelity evaluation of the THOR advanced frontal crash dummy. Proceedings of the IRCOBI Conference 2000, Montpellier; France.

Shaw, G., Parent, D., Purtsezov, S., Lessley, D., Crandall, J., Kent, R., Guillemot, H., Ridella, S. A., Takhounts, R., Martin, P., 2009. Impact Response of Restrained PMHS in Frontal Sled Tests: Skeletal Deformation Patterns Under Seat Belt Loading. Stapp Car Crash Journal 53, 1-48.

Society of Automotive Engineers. Instrumentation for impact test. Document no. J211. Society of Automotive Engineers, Warrendale, PA, 1998.

Sunnevång C, Lecuyer E, Hynd D, Carroll J, Kruse D, Boström O. Evaluation of near-side oblique frontal impacts using THOR with SD3 shoulder. Traffic Inj. Prev. 2014;15.

Tornvall, F. V., Svensson, M. Y., Davidsson, J., Flogard, A., Kallieris, D., Haland, Y., 2005. Frontal impact dummy kinematics in oblique frontal collisions: evaluation against post mortem human subject test data. Traffic Injury Prevention 6, 340-350.

Yoganandan N, Pintar F, Schlick M, Moore J, Maiman D. Comparison of Head-Neck Responses in Frontal Impacts Using Restrained Human Surrogates. Ann Adv Automot Med. 2011;55:181-91. 


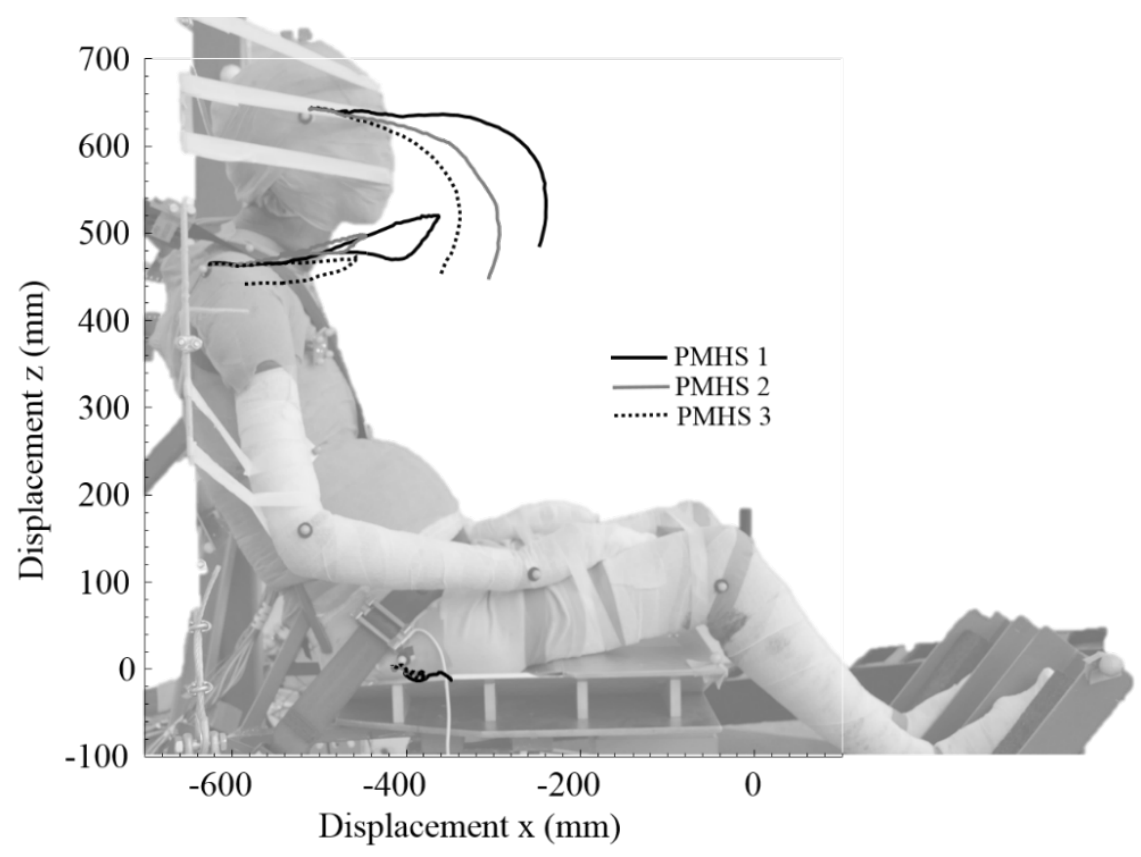

Figure 1 Trajectories of the head CG, mid-Ac and mid-HP in the sagittal plane of the occupant. Individual trajectories have been assumed to have the same origin to facilitate the comparison across the three subjects.

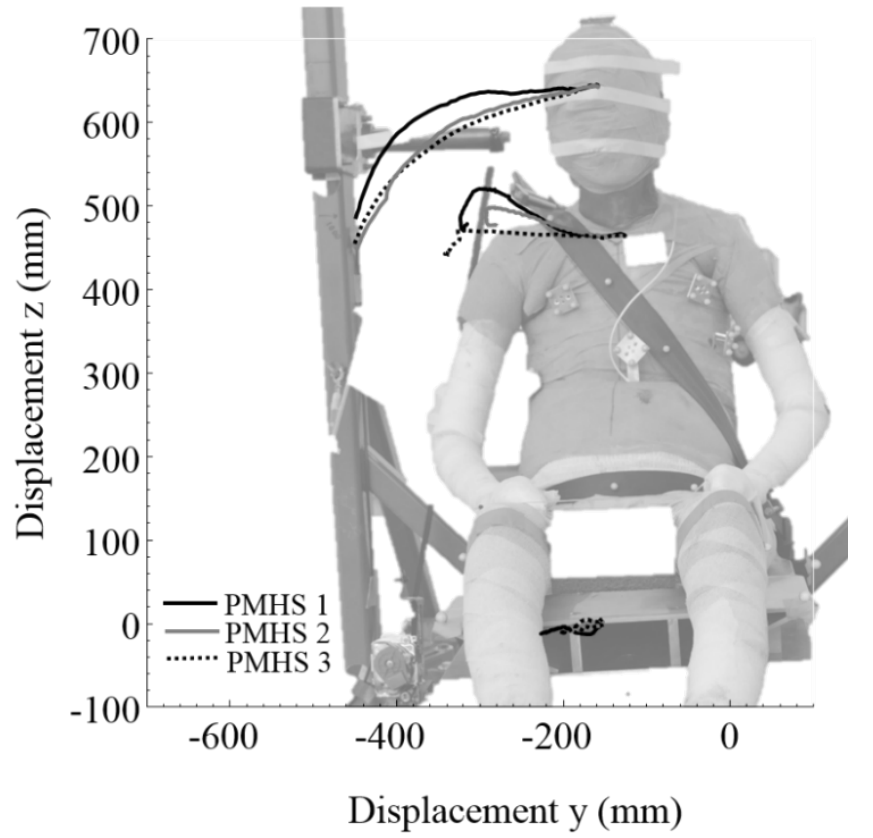

Figure 2 Trajectories of the head CG, mid-Ac and mid-HP locations in the frontal plane of the occupant. Individual trajectories have been assumed to have the same origin to facilitate the comparison across the three subjects. Note that the picture of the occupant shows the approximate location of these anatomical landmarks, but the different nonperpendicular orientation of the occupant's frontal plane with respect to the plane of the photograph prevents from matching the location of the mid-hip location on the occupant. 


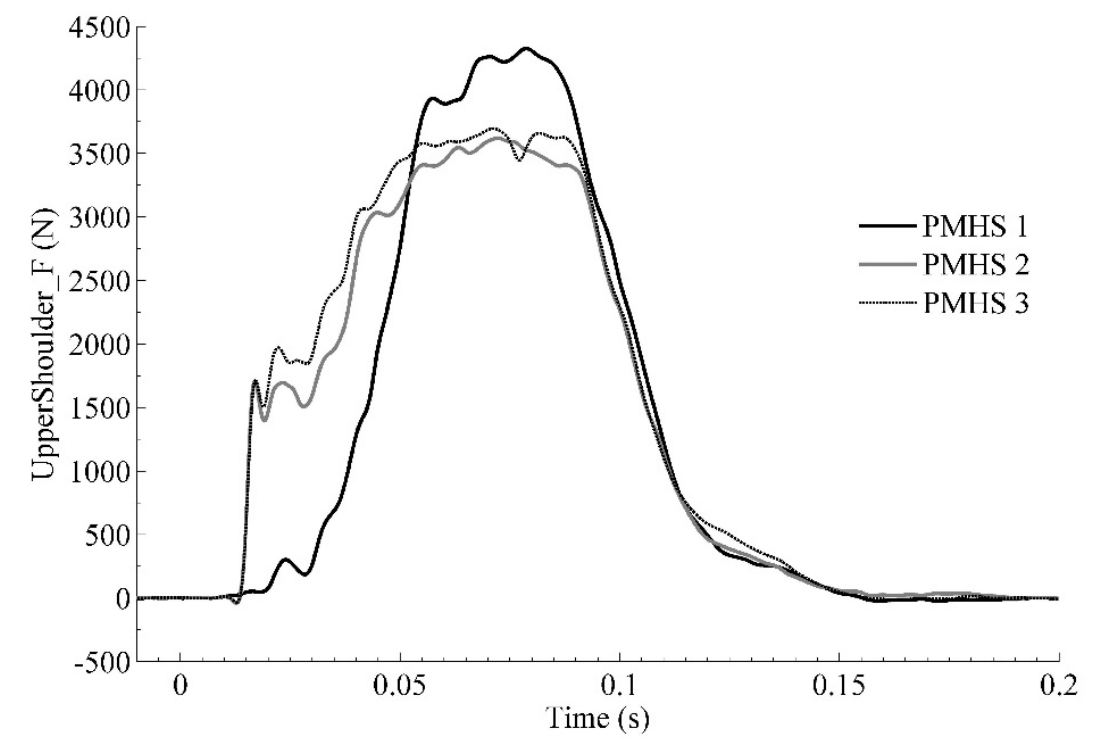

Figure 3 Time history plot of the seat belt forces measured between the occupant's shoulder and the D-ring.

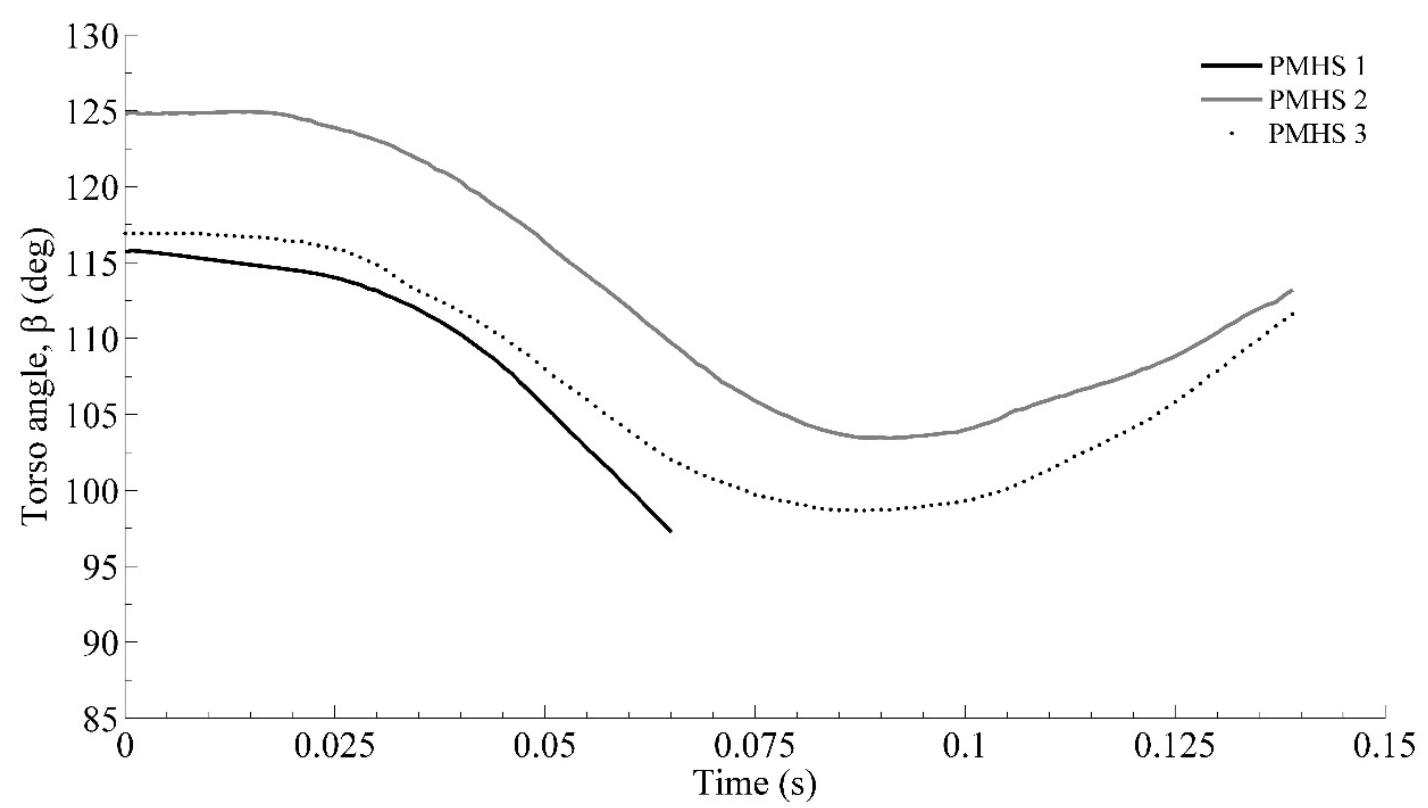

Figure 4 Time history of the torso angle in the sagittal occupant's plane. 
Table 1 PMHS demographics and peak measured results

\begin{tabular}{|c|c|c|c|}
\hline & PMHS 1 & PMHS 2 & PMHS 3 \\
\hline & \multicolumn{3}{|c|}{ Demographics } \\
\hline Age & 60 & 66 & 68 \\
\hline Stature $(\mathrm{cm})$ & 170.5 & 175 & 169 \\
\hline Weight (kg) & 65 & 50 & 68 \\
\hline Sex & Male & Male & Male \\
\hline Sitting height $(\mathrm{cm})$ & 101.4 & 96.3 & 103.8 \\
\hline Cause of death & Lung cancer & Pancreatic cancer & Lung cancer \\
\hline PMHS ID & $0010 \mathrm{M}$ & $0009 \mathrm{M}$ & $0011 \mathrm{M}$ \\
\hline Test number & 1441 & 1443 & 1447 \\
\hline Restraint type & $\begin{array}{c}\text { FL, lap belt PT (1.5 } \\
\text { kN) }\end{array}$ & $\begin{array}{l}\text { FL, shoulder PT }(\mathrm{XX} \mathrm{kN}) \\
\text { and lap belt PT }(1.5 \mathrm{kN})\end{array}$ & $\begin{array}{c}\text { FL, shoulder PT (XX kN) } \\
\text { and lap belt PT }(1.5 \mathrm{kN})\end{array}$ \\
\hline \multirow[t]{2}{*}{ Impact speed $(\mathrm{km} / \mathrm{h})$} & 34.3 & 34.1 & 34.3 \\
\hline & \multicolumn{3}{|c|}{ Test results } \\
\hline Head excursion $x(\mathrm{~mm})$ & 271.4 & 216.7 & 171.5 \\
\hline Head excursion y (mm) & 291.1 & 290.0 & 292.1 \\
\hline Mid H-point excursion x (mm) & 51.2 & 20.9 & 21.9 \\
\hline Head acceleration resultant (g) & 71.1 & 53.8 & 55.1 \\
\hline Head flexion angular rate (rad/s) & 38.5 & 34.4 & 33.0 \\
\hline $\begin{array}{l}\text { Upper spine flexion angular rate } \\
\text { (rad/s) }\end{array}$ & 29.2 & 27.8 & 29.0 \\
\hline Upper shoulder belt force $(\mathrm{N})$ & 4325.2 & 3623.1 & 3695.9 \\
\hline Lower shoulder belt force $(\mathrm{N})$ & 4845.1 & 3853.2 & 4304.0 \\
\hline Inner lap belt force $(\mathrm{N})$ & 3258.6 & 3313.9 & 3853.4 \\
\hline Outer lap belt force $(\mathrm{N})$ & 3958.7 & 3991.0 & 4109.1 \\
\hline Sternal acceleration (g) & -68.2 & -82.3 & -56.7 \\
\hline T1 acceleration $(\mathrm{g})$ & 44.3 & 39.6 & 34.9 \\
\hline T8 acceleration (g) & 36.4 & 32.8 & 30.2 \\
\hline L2 acceleration (g) & 35.3 & 39.1 & 74.1 \\
\hline Pelvis acceleration $(\mathrm{g})^{*}$ & -- & -- & 62.9 \\
\hline Torso min pitch angle (deg) & 98.7 & 103.4 & 97.2 \\
\hline
\end{tabular}

* The pelvic accelerometer block hit the seat in the first test due to the oblique motion of the pelvis. No instrumentation was added to the second test. In the third test, a new tridimensional acceleration block was added to the pelvis, but it was attached laterally to the right iliac crest to avoid interference with the seat hardware.

Table 2 Injury summary

\begin{tabular}{|l|l|l|l|}
\hline & PMHS 1 & PMHS 2 & PMHS 3 \\
\hline Ribs & $\begin{array}{l}\text { Right aspect: } 5 \mathrm{fx} \\
\text { Left aspect: } 6 \mathrm{fx}\end{array}$ & $\begin{array}{l}\text { Right aspect: } 15 \mathrm{fx} \\
\text { Left aspect: } 7 \mathrm{fx}\end{array}$ & $\begin{array}{l}\text { Right aspect: } 6 \mathrm{fx} \\
\text { Left aspect: } 1 \mathrm{fx}\end{array}$ \\
\hline Sternum & 2 fx (manubrium, body) & -- & -- \\
\hline Clavicle & $\begin{array}{l}\text { Right: fx proximal half, } \\
\text { displaced, comminuted }\end{array}$ & $\begin{array}{l}\text { Right: fx proximal third } \\
\text { posterior aspect, non- } \\
\text { displaced. }\end{array}$ & $\begin{array}{l}\text { Right: fx proximal third } \\
\text { displaced, fx distal third }\end{array}$ \\
\hline $\begin{array}{l}\text { Cervical } \\
\text { Spine }\end{array}$ & Subluxation atlantoaxial & -- & Subluxation atlantoaxial \\
\hline $\begin{array}{l}\text { Thoracic } \\
\text { Spine }\end{array}$ & $\begin{array}{l}\text { T1, T2, T3, T4: fracture of the } \\
\text { right lamina, involving the } \\
\text { right transverse process. }\end{array}$ & -- & -- \\
\hline Pelvis & -- & $\begin{array}{l}\text { Pubic left ramus fx, non- } \\
\text { displaced }\end{array}$ & -- \\
\hline Superficial & -- & -- & Neck abrasion \\
\hline
\end{tabular}

